\title{
CARACTERIZAÇÃO ESTRUTURAL DE FILMES FINOS POR TÉCNICAS DE RAIOS X
}

\section{Autores: Victor Blaia Barrera*, Lisandro P. Cardoso, Diego Scolfaro da Silva, Odilon D.D. Couto Jr}

\section{Resumo}

O objetivo deste trabalho é verificar as possíveis alterações nas propriedades estruturais de filmes de ZnO obtidos por deposição de camadas atômicas (ALD) sobre substratos de Si(001) em função dos tempos de pulso e purga de água para limpeza da câmara, durante o crescimento, usando a difratometria de raios $X$ em policristais. Os resultados mostram filmes com uma visível orientação preferencial na direção [001] com o tempo de purga, e que não há alteração nas propriedades estruturais dos filmes quando pulsos mais longos são utilizados.

\section{Palavras-chave:}

Difração de $R X$, filmes finos, propriedades estruturais

\section{Introdução}

O crescimento e a caracterização óptica de filmes de ZnO obtidos por deposição de camadas atômicas (ALD) sobre Si realizados pelo Grupo de Propriedades Ópticas (GPO) do Departamento de Física da Matéria Condensada (DFMC), do Instituto de Física Gleb Wataghin (IFGW), visam a obtenção de dispositivos ópticos (cavidades fotônicas). Neste trabalho, a análise estrutural por difração de raios $X$, do efeito do substrato e orientação no crescimento dos filmes é realizada usando a difratometria de raios $\mathrm{X}$ dos filmes de $\mathrm{ZnO}$ associado ao método de Rietveld de refinamento de estrutura.

\section{Resultados e Discussão}

Foram medidos dois conjuntos de amostras obtidos no com crescimento por ALD em ciclos, cada ciclo é sequência de pulsos dos precursores com purga/limpeza da câmara. Em cada ciclo: 1) pulso do precursor do ZnO (DeZ-Dietil-Zinco); 2) purga do DeZ; 3) pulso de água; 4) purga da água. O primeiro conjunto (\#17, \#18, \#19 e \#23) apresenta aumento progressivo no tempo de purga, e o segundo (\#20, \#21 e \#22) pulsos mais longos que devem manter a estrutura dos filmes. Nas figuras, difratogramas de raios $X$ indexados mostram filmes finos de $\mathrm{ZnO}$, sistema hexagonal (P63mc), parâmetros de rede $\mathrm{a}=3,2093 \pm 0,001 \AA \AA$ e $c=5,1511 \pm 0,015 \AA$ A, por Rietveld.

Tabela 1. Parâmetros do crescimento por ALD.

\begin{tabular}{|c|c|c|c|}
\hline Amostra & Precursor & Pulso (ms) & Purga (s) \\
\hline \multirow{2}{*}{$\mathrm{ZnO}-017$} & DEZn & 500 & 1,0 \\
\hline & $\mathrm{H}_{2} \mathrm{O}$ & 500 & 1,5 \\
\hline \multirow{2}{*}{$\mathrm{ZnO}-018$} & DEZn & 500 & 2,0 \\
\hline & $\mathrm{H}_{2} \mathrm{O}$ & 500 & 3,0 \\
\hline \multirow{2}{*}{$\mathrm{ZnO}-019$} & DEZn & 500 & 6,0 \\
\hline & $\mathrm{H}_{2} \mathrm{O}$ & 500 & 9,0 \\
\hline \multirow{2}{*}{$\mathrm{ZnO}-020$} & DEZn & 500 & 2,0 \\
\hline & $\mathrm{H}_{2} \mathrm{O}$ & 500 & 3,0 \\
\hline \multirow{2}{*}{$\mathrm{ZnO}-021$} & DEZn & 1000 & 2,0 \\
\hline & $\mathrm{H}_{2} \mathrm{O}$ & 1000 & 3,0 \\
\hline \multirow{2}{*}{$\mathrm{ZnO}-022$} & DEZn & 2000 & 2,0 \\
\hline & $\mathrm{H}_{2} \mathrm{O}$ & 2000 & 3,0 \\
\hline \multirow{2}{*}{$\mathrm{ZnO}-023$} & DEZn & 1000 & 8,0 \\
\hline & $\mathrm{H}_{2} \mathrm{O}$ & 1000 & 12,0 \\
\hline
\end{tabular}

\section{Conclusões}

Os resultados dos filmes $\mathrm{ZnO} / \mathrm{Si}(001)$ mostram orientação preferencial [001] com o tempo de purga, pela razão picos $(002) /(100)$, e que não há alteração nas propriedades estruturais dos filmes com pulsos mais longos, i.e., a estrutura cristalina é estável.

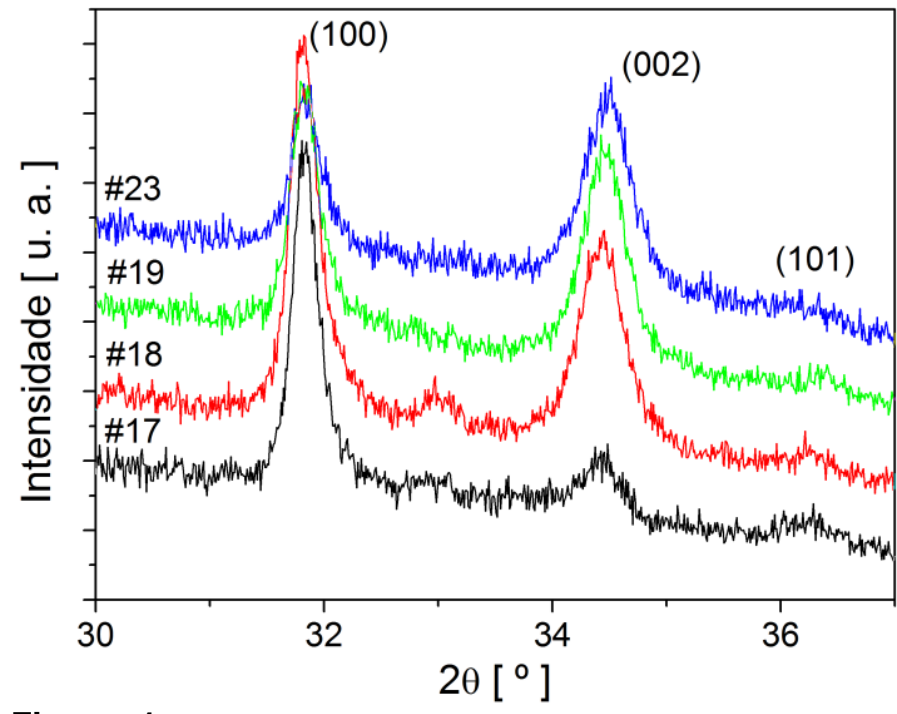

Figura 1. Difratogramas de $R X$ para amostras de filmes $\mathrm{ZnO} / \mathrm{Si}(001)$ com diferentes tempos de purga da água.

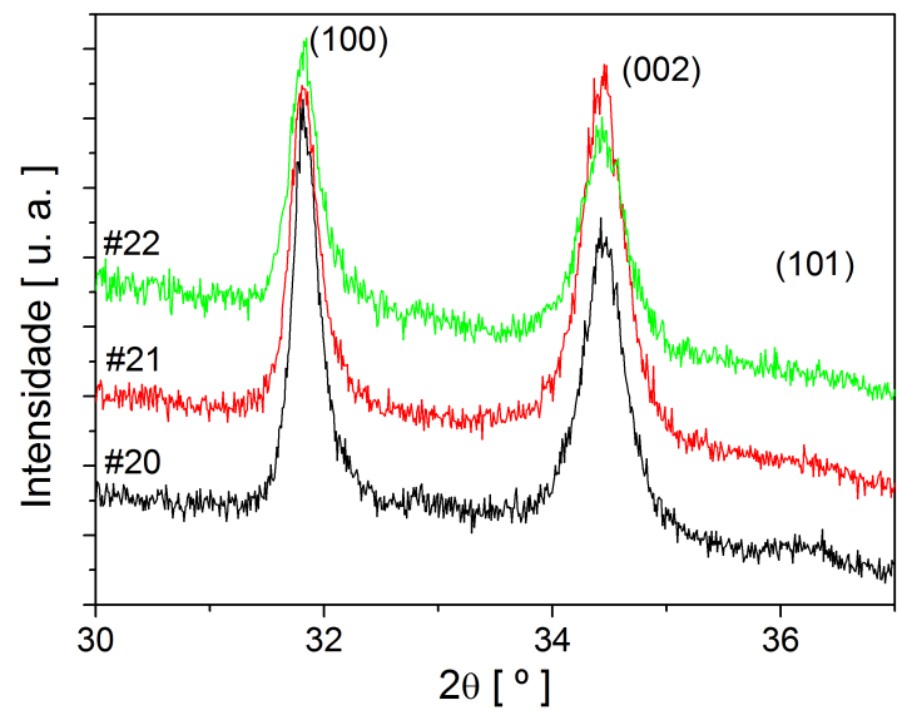

Figura 2. Difratogramas de $R X$ para amostras de filmes $\mathrm{ZnO} / \mathrm{Si}(001)$ com diferentes tempos de pulsos de água.

\section{Agradecimentos}

Agradeço ao Prof. Lisandro Pavie Cardoso pelos ensinamentos, ao aluno Diego Scolfaro da Silva e ao Prof. Odilon D. D. Couto Jr a preparação das amostras de filmes e ao PIBIC pelo fomento a essa pesquisa. 